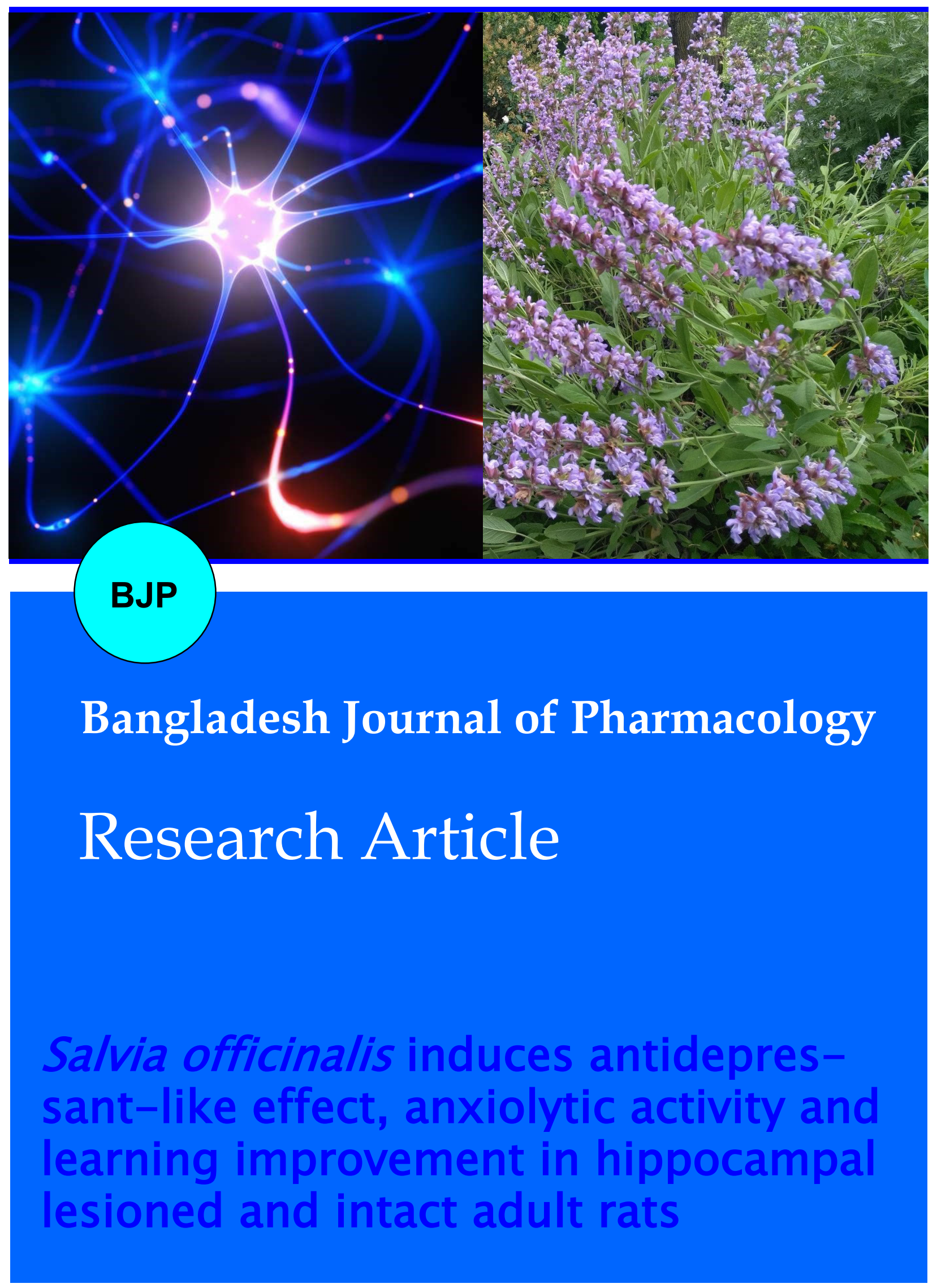




\title{
Salvia officinalis induces antidepressant-like effect, anxiolytic activity and learning improvement in hippocampal lesioned and intact adult rats
}

\author{
Zineb El Gabbas', Kenza Bezza' ${ }^{1}$, Jawad Laadraoui', Rachida Makbal², Rachida \\ Aboufatima $^{3}$ and Abderrahman Chait ${ }^{1}$
}

${ }^{1}$ Laboratory of Pharmacology, Neurobiology and Behavior, Semlalia Faculty of Sciences, Cadi Ayyad University, Marrakech, Morocco; ' ${ }^{2}$ Laboratory of Biotechnology, Protection and Valorization of Plant Resources, Phytochemistry and Pharmacology of Aromatic and Medicinal Plants Unit. Department of Biology, Faculty of Sciences Semlalia, Cadi Ayyad University, Marrakech, Morocco; ${ }^{3}$ Laboratory of Génie Biologique, Sultan Moulay Slimane University, Faculty of Sciences et Techniques, Beni Mellal, Morocco.

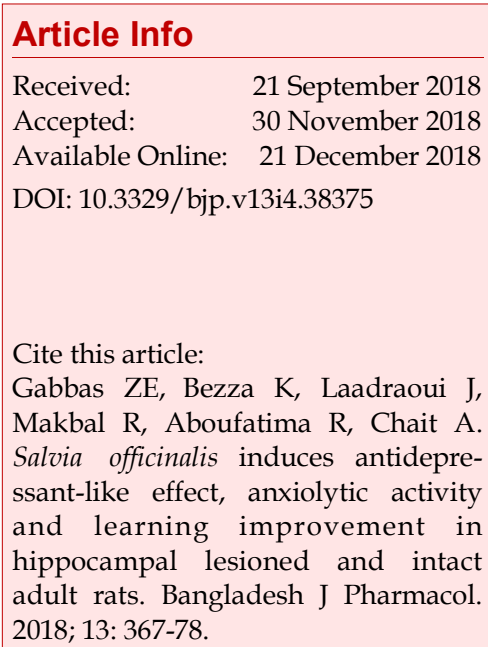

\begin{abstract}
The anxiolytic and antidepressant like effects of Salvia officinalis extract (50, 100 and $200 \mathrm{mg} / \mathrm{kg}$ ) were evaluated using marble burying, forced swimming and open-field tests in intact and hippocampal lesioned rats. Additionally, $S$. officinalis was evaluated on rat's memory using conditioned learning test and we screened the methanolic extract for anti-oxidant activity, phytochemical and high performance liquid chromatography analyses. The administration of sage extract showed a significant reduction of immobility time in lesioned and intact animals during the forced swim test and anxiolytic effect in marble burying test. In the case of conditioned learning paradigm, memory enhancement was observed in sage treated group which indicates a cognition improvement. These activities seem to be related to the anti-oxidant capacity and the phytochemicals (phenolic, flavonoid, and tannin) detected into the extract of S. officinalis. The findings show that the methanolic extract of sage possess antidepressant-like effect, anxiolytic activity and also may contain bioactive compounds that stimulate learning in rat.
\end{abstract}

\section{Introduction}

Several synthetic and chemical drugs have been introduced to treat patients with various neurological disorders, but their therapeutic effects have modest efficacy and most of them are associated with several adverse effects indicating need of better-tolerated and more efficacious treatments (Kim and Oh, 2012). Medicinal plants have been a major source of natural active compounds that can provide important options for developing drugs for the treatment of different mood and neurological disorders.

Salvia officinalis L. (Lamiaceae, common sage) is an aromatic and medicinal plant native to the Mediterra- nean region, extensively used since ancient times in folk medicine (Penso, 1983). It is known in Arabic as "almufassiha" because it helps who take it to talk fluently, and in Morocco, it is also called Salmiya, commonly used in the food especially to flavor the tea and for the treatment of various diseases. The leaves of S. officinalis have a very old reputation as traditional herbal remedies and have been recorded to be used as cognitionenhancing agents (Kennedy and Scholey, 2006; Perry et al., 1999). Experimental evidence supports several biological activities for different types of S. officinalis extracts, including anti-oxidant (Lu and Yeap Foo, 2001), antihyperglycaemic (Alarcon-Aguilar et al., 2002; Behradmanesh et al., 2013), gastroprotective (Mayer et 
al., 2009), anti-inflammatory and also anti-nociceptive activities (Rodrigues et al., 2012). Systematic and mechanistic studies of the effects of $S$. officinalis extracts have revealed multiple activities potentially relevant to brain function, and some reports showed that ethanolic extract of $S$. officinalis potentiates the memory retention and interacts with muscarinic and nicotinic cholinergic systems involved in the memory retention process (Eidi et al., 2006). Even the efficacy of the leaves of $S$. officinalis extract in the management of Alzheimer's disease, the treatment of depression, and memory disorders have been reported (Akhondzadeh et al., 2003; Howes et al., 2003; Perry et al., 2002; Savelev et al., 2004).

With regard to the possible effects of $S$. officinalis on behavior, this work aimed to investigate the effect of methanolic extract of S. officinalis on depression, anxiety and learning in hippocampal lesioned and normal adult rats.

\section{Materials and Methods \\ Plant collection and identification}

S. officinalis leaves were collected from the Ourika region, Morocco in March, 2013 and the plant's identity was confirmed by Prof. Ouhammou in the Faculty of Sciences Semlalia, University Cadi Ayyad Marrakech, Morocco. A voucher specimen of the plant has been deposited at the herbarium of the Faculty under the number MARK-10004.

The plant was cleaned and shed dried at $40^{\circ} \mathrm{C}$. The dried leaves of the plant were triturated in order to obtain a powder.

\section{Preparation of methanolic extract}

Dried and ground leaves (110 g) were used for extraction with methanol $(600 \mathrm{~mL})$ in a soxhlet apparatus for 72 hours. After extraction the solvent was evaporated by a rotavapor (Stuart ${ }^{\circledR}$ RE300, Bibby Scientific, UK). The final weight of the extract was $34.45 \mathrm{~g}$.

\section{Determination of total polyphenols content}

The total phenolic content of the extract was determined using Folin Ciocalteu method as described previously (Singleton and Rossi, 1965). Briefly, $100 \mu \mathrm{L}$ of the properly diluted extract was mixed with $3.9 \mathrm{~mL}$ of distilled water followed by $100 \mu \mathrm{L}$ of Folin-Ciocalteu reagent. After $3 \mathrm{~min}, 1 \mathrm{~mL}$ of $20 \%$ sodium carbonate $\left(\mathrm{Na}_{2} \mathrm{CO}_{3}\right)$ was added. The mixture was shaken and incubated for 1 hour at room temperature in the dark. The absorbance was measured at $725 \mathrm{~nm}$ against a blank using a UV-vis spectrophotometer. The total phenolic concentration is expressed as $\mathrm{mg}$ equivalent gallic acid per gram of the dry matter. All assays were carried out in triplicate.

\section{Determination of total flavonoids}

The flavonoids content was determined by aluminum trichloride method using catechin as reference compound (Zhishen et al., 1999). A volume of $200 \mu \mathrm{L}$ of extract was mixed with $800 \mu \mathrm{L}$ of distilled water added to $60 \mu \mathrm{L}$ of $5 \% \mathrm{NaNO}_{2}$ solution. The mixture was allowed to stand for $6 \mathrm{~min}$, then $40 \mu \mathrm{L}$ of aluminum trichloride $(10 \%)$ was added and incubated for $5 \mathrm{~min}$, followed by the addition of $400 \mu \mathrm{L}$ of $1 \mathrm{M} \mathrm{NaOH} .500 \mu \mathrm{L}$ of distilled water are added to the reaction medium. Immediately, the mixture was agitated in order to homogenize the content. After 15 min of incubation, the absorbance of the pinkish mixture was measured at 510 $\mathrm{nm}$. The content of total flavonoids of studied extract was expressed as $\mathrm{mg}$ equivalent catechin per gram of the DM.

\section{Total condensed tannin contents}

The quantities of condensed tannins are estimated using the method to vanillin in acid medium ( $\mathrm{Xu}$ and Chang, 2007). A volume of $200 \mu \mathrm{L}$ of the extract is introduced in two test tubes separated (one for the sample and the other for the witness). Then, $2 \mathrm{~mL}$ of a solution of vanillin ( $4 \%$ in methanol) and $1 \mathrm{~mL}$ of concentrated hydrochloric acid are added. After $15 \mathrm{~min}$ incubation of the obtained mixture, the absorbance was read at $500 \mathrm{~nm}$ with the aid of a spectrophotometer UV -vis. The results were expressed as mg equivalent catechin per $g$ of the dry matter.

\section{DPPH Free radical-scavenging activity}

The total anti-oxidant capacity measures the free radical scavenging capacity of S. officinalis extract. An aliquot of $100 \mu \mathrm{L}$ of different sample or standard concentrations (butylated hydroxytoluene, quercetin, ascorbic acid and a-tocopherol) was added to $2.9 \mathrm{~mL}$ of the methanolic DPPH solution $(0.004 \%)$ freshly prepared. In parallel, the negative control was prepared by mixing $100 \mu \mathrm{L}$ of methanol with $2.9 \mathrm{~mL}$ of methanolic DPPH at the same concentration used. The mixture was shaken and kept in the dark at room temperature for $30 \mathrm{~min}$ and the absorbance was recorded at $517 \mathrm{~nm}$ against a blank containing all reagents except the test sample. Assays were carried out in triplicate. The following equation was used to determine the percentage of the radical scavenging activity of each extract.

Inhibition $(\%)=[$ control absorbance - sample absorbance)/control absorbance] $\times 100$

\section{$\beta$-Carotene/linoleic acid bleaching assay}

The anti-oxidant activity of the samples was determined using the $\beta$-carotene/linoleic acid test. The assay was carried out as described previously (Miraliakbari and Shahidi, 2008). A stock solution of $\beta$ carotene and linoleic acid was prepared by adding together $0.5 \mathrm{mg} \beta$-carotene in $1 \mathrm{~mL}$ chloroform, $25 \mu \mathrm{L}$ 
linoleicacid and $200 \mathrm{mg}$ Tween 20. The chloroform was removed using a rotary evaporator, and distilled water (50 mL) was subsequently added to the residue slowly with vigorous agitation, to form an emulsion. $350 \mu \mathrm{L}$ of $S$. officinalis extract solution or reference anti-oxidant (butylated hydroxytoluene) at various concentrations were added to $2.5 \mathrm{~mL}$ of the above emulsion. The test and control (containing water in place of sample) tubes were capped and incubated at $50^{\circ} \mathrm{C}$ for 2 hours. The absorbance of the emulsion at $470 \mathrm{~nm}$ was determined. All determinations were performed in triplicate.

Anti-oxidant activity (AA) was calculated as percent inhibition relative to the control:

$\mathrm{I} \%=\left[\left(\mathrm{A}_{\text {sample }} 2-\mathrm{A}_{\text {blank }} 2\right.\right.$ hours $) /\left(\mathrm{A}_{\text {initial blank }}-\mathrm{A}_{\text {blank }} 2\right.$ hours)] $\times 100$.

Where, $\mathrm{A}_{\text {sample }} 2$ hours, $\mathrm{A}_{\text {blank }} 2$ hours are the absorbance of the test compound and control respectively after 2 hours assay and a initial blank is the absorbance of control at the beginning of the experiment

The sample concentration providing 50\% inhibition ( $\left.\mathrm{IC}_{50}\right)$ was measured by plotting inhibition percentages against the sample concentrations.

\section{Iron (II) chelating activity}

The ability of $S$. Officinalis extracts to reduce $\mathrm{FeCl}_{3}$ to $\mathrm{FeCl}_{2}$ was investigated using the method (Oyaizu, 1986). $1 \mathrm{~mL}$ of the tested sample (S. officinalis extract or standard (butylated hydroxytoluene, quercetin, atocopherol and ascorbic acid) was mixed with the phosphate buffer $(2.5 \mathrm{~mL}, 0.2 \mathrm{M}, \mathrm{pH}$ 6.6) and potassium ferricyanide $(2.5 \mathrm{~mL}, 1 \%)$. The mixture was then incubated at $50^{\circ} \mathrm{C}$ for $20 \mathrm{~min}$. Subsequently, $2.5 \mathrm{~mL}$ of trichloroacetic acid (10\%) was added to the mixture, which was then centrifuged for $10 \mathrm{~min}$ at 3,000 rpm. Finally, the upper layer of the solution $(2.5 \mathrm{~mL})$ was mixed with distilled water $(2.5 \mathrm{~mL})$ and $\mathrm{FeCl}_{3}(0.5 \mathrm{~mL}$, $0.1 \%)$, and the absorbance was measured at $700 \mathrm{~nm}$ in a spectrophotometer.

\section{HPLC analysis of S. Officinalis extract}

The identification of phenolic monomers was conducted using a high-performance liquid chromatography (Knauer) equipped with a (K-1001) pump and a PDA detector (200-700 UV-vis) operating at $280 \mathrm{~nm}$. The column was $(4.6 \times 250 \mathrm{~mm})$ (Eurospher II 100-5), and the temperature was set at $25^{\circ} \mathrm{C}$. The flow rate was 1 $\mathrm{mL} / \mathrm{min}$ and the sample volume injected was $2 \mathrm{~mL}$. Acidified water (A) and acetonitrile (B) mixture were chosen as the optimal mobile phase for a total running time of $60 \mathrm{~min}$. The identification of phenolic compounds was executed by comparison of retention times and UV-vis spectra with the standards.

\section{Experimental animals}

Male Sprague-Dawley rats, from the animal facility of the faculty of Sciences Semlalia, Marrakech, Morocco weighing 300-350 $\mathrm{g}$ were used in this study. The animals, housed in individual plastic cages, were kept at constant room temperature $\left(21 \pm 2{ }^{\circ} \mathrm{C}\right)$ and relative humidity $(60 \%)$ with a 12 hours light/dark cycle (dark from 7 P.M.) and had free access to water and food.

\section{Acute toxicity test}

Acute toxicity test was performed on mice weighing about 17 to $25 \mathrm{~g}$ were divided equally into different groups $(n=6)$ and fasted overnight, but provided with water ad libitum. On the test day, the methanolic extract was given by gavage in the doses of $1,2,3,4$ and $5 \mathrm{~g} / \mathrm{kg}$ $(10 \mathrm{~mL} / \mathrm{kg})$. To detect signs of toxicity and death, mice were observed for $2,4,6,8,12$ and 24 hours postextract administration. The mice were also observed daily for up to 14 days to detect any possible delayed death.

\section{Drugs and treatments}

The drugs administered to the rats were imipramine (Novartis, $30 \mathrm{mg} / \mathrm{kg}$ ), diazepam (F. Hoffmann-La Roche, Switzerland, $1 \mathrm{mg} / \mathrm{kg}$ ), and $S$. Officinalis methanolic extract $(50 \mathrm{mg} / \mathrm{kg})$. Imipramine was selected as standard drug (positive control) for depression in the forced swim test, diazepam as reference drug (positive control) for anxiolytic activity and saline $(0.9 \% \mathrm{NaCl})$ as control. All drugs and vehicle were injected intraperitoneally. The injection volume was $0.1 \mathrm{~mL} / 100 \mathrm{~g}$ body weight.

Thirty min after intraperitoneal treatment, the animals were submitted to behavioral tests (forced swim test, marble burying test and conditioned learning test).

\section{Hippocampal lesion}

After the acclimatization to the laboratory conditions, all rats were divided into different groups:

A control group [control-saline, $n=6$, positive-control, $(n=6)]$ remained free of any surgical manipulation, treated group with sage $(n=6)$. In the sham group $(n=$ 6), animals underwent the same surgical procedure at the same coordinates to those employed in the lesioned group [lesioned $(n=6)$, lesioned plus sage $(n=6)$ ] except the electric current.

For the hippocampal lesion and after thiopental anesthesia (60 mg/kg body weight), the rats were mounted on a stereotaxic frame (Horseley-Clark). The hippocampus was damaged at one anteroposterior site in relation to the interaural zero point. All coordinates were obtained from the rat brain atlas (Paxinos and Watson, 1998) with anteroposterior, mediolateral and dorsoventral positions referenced from Bregma: anteroposterior, $-5.2 \mathrm{~mm}$, mediolateral, $+4.8 \mathrm{~mm}$, dorsoventral, $+4.8 \mathrm{~mm}$. The unilateral electrolytic lesion was made with a lesion-generating device (GRASS, D.C. 
LM5A, USA) by passing $2 \mathrm{~mA} \mathrm{DC}$ cathodal current for $15 \mathrm{sec}$ (Ramos, 2008) through a monopolar stainless steel electrode insulated with INSL-X except for the 0.5 $\mathrm{mm}$ tip. The rats in the sham group underwent the same surgical procedure at the same coordinates except the electric current.

\section{Antidepressant-like activity of S. officinalis extract}

The forced swim test is one of the most used assays of depressant-like activity in rodent. It was performed according to the method described previously (Porsolt et al., 1977). A vertical plexiglas cylinder (40 cm high, 20 $\mathrm{cm}$ in diameter and depth of $20 \mathrm{~cm}$ ) was filled with water at $25^{\circ} \mathrm{C}$. The rats were first subjected to pre-swim by placing each of them in the cylinder for $15 \mathrm{~min}$. The day of test, and 24 hours after the pre swim, each rat was forced to swim in the cylinder for $6 \mathrm{~min}$ and the duration of floating (i.e. the time during which the rat made only the small movements necessary to keep its heads above water) was scored. The soiled water was changed between the tests.

\section{Effect of S. Officinalis extract on locomotor activity}

In order to evaluate the possible effects of S. officinalis on locomotor activities, a group of tested rats was evaluated in the open-field test as previously described (Katz et al., 1981). Rats were individually placed in a wooden box $(80 \times 80 \times 40 \mathrm{~cm})$ divided into 25 squares of equal areas. The number of crossings defined as the rectangles crossed by the animal with its four paws was registered during a 5 min period. During the test time, the animal's movements in the field were quantified by counting the number of crossings (at least three paws in a square) and the number of rearing which was defined

\section{Box 1: Marble Burying Test}

\section{Principle}

The lesion(s) in the hippocampus and septum reduce the digging

\section{Uses}

This test is an useful model of anxiety, obsessive compulsivedisorder and neophobia. The test has predictive validity for screening of novel anxiolytic or antidepressant.

\section{Requirements}

Glass toy marbles; Polycarbonate rat cage; Wood chip bedding

\section{Preparation of the cages}

1. The polycarbonate rat cage $(26 \times 48 \times 20 \mathrm{~cm})$ with fitted filter-top cover was filled with wood chip bedding (about 5 $\mathrm{cm}$ depth), lightly tamped down to make a flat and even surface.

2. A regular pattern of glass toy marbles were placed on the surface, evenly spaced (about $4 \mathrm{~cm}$ apart).

3. Use a stop watch for counting the time $(30 \mathrm{~min}$ for each

as the animal standing upright on its hind legs (wall rears and free rears). The number of crossings was considered as indicative of locomotor activity. The floor of the open-field apparatus was cleaned with $10 \%$ ethanol at the end of each test to remove any olfactory cues.

\section{Effect of S. officinalis extract on learning}

In this experiment, the testing was performed into two equally sized compartments (right and left) $(30 \times 25 \times 50$ $\mathrm{cm}$ ) connected by an opaque wood door (with one hole). The box was covered by a hinged roof of clear Plexi-glass with numerous holes to allow ventilation and the floor was made of stainless steel rods $(2.5 \mathrm{~mm}$ in diameter) that were separated by a distance of $1 \mathrm{~cm}$. The experimental room was illuminated and quit.

All rats were trained initially to the box for $10 \mathrm{~min}$ and immediately followed by a series of 10 trials $=1$ sequence. Each trial consisted of a $3 \mathrm{sec}$ of sound stimulation (conditioned stimulus), which was an $80 \mathrm{db}$ tone presented through a bell centrally mounted about $20 \mathrm{~cm}$ above the box. The conditioned stimulus was followed by an electrical stimulation 1, $2 \mathrm{~mA}$ foot-shock of $30 \mathrm{sec}$ as unconditioned stimulus delivered through the grid floor. The unconditioned stimulus was terminated when the animal crossed to the other compartment. If the rat crosses to the other compartment during conditioned stimulus, before unconditioned stimulus onset, successful acquisition of learning response was recorded.

Each animal was tested for 10 sequences and $30 \mathrm{~min}$ after methanolic extract injection.

test)

\section{Test}

1. Place one rat into a conner of a cage on bedding carefully and left for $30 \mathrm{~min}$

2. The number of marbles buried up to $2 / 3$ their depth within the bedding was counted

\section{Advantages}

1. Readily available to most laboratories and is not expensive

2. Simple to apply

3. Easy to score reliably

Limitation

The neuronal circuitry of the behavior is not clearly elucidated.

\section{References}

Ho et al., 2002; Nicolas et al., 2006; Gyertyán, 1995; Hedlund and Sutcliffe, 2007; Dekeyne, 2005; Harasawa et al., 2006; Palucha and Pilc, 2007; Shimazaki et al., 2004; Deacon and Rawlins, 2005; Dringenberg et al., 2006 


\section{Histological verification}

At the end of all behavioral experiments, rats were anesthetized with thiopental (60 mg/kg i.p.) and perfused transcardially with $50 \mathrm{~mL}$ of $0.9 \%$ saline followed by $3.2 \%$ paraformaldehyde. After perfusion, the brains were removed and post-fixed for 24 hours in $3.2 \%$ paraformaldehyde, then stored in 30\% sucrose. Coronal sections $(50 \mu \mathrm{m})$ were sectioning with the cryostat (Leica Microsystems, Germany), stained with $0.5 \%$ toluidine blue, mounted on glass microscope slides and examined under a microscope (Leica Microsystems, Germany) where the lesions and probe placement could be seen. Any subjects with misplaced cannula or significant damage around the injection site were excluded from the subsequent statistical analyses of the behavioral data.

\section{Statistical analysis}

All experimental results are given as the mean \pm S.E.M. For the behavioral measures in the forced swim, marble burying and conditioned learning tests, the time spent immobile and sequences for all groups were analyzed using a one-way analysis of variance (ANOVA). If the ANOVA revealed a significant main effect, a Tukey post-hoc analysis was performed to compare between the specific groups. Statistical significance was set to $\mathrm{p}<0.05$. The SigmaPlot 12.5 software was used for statistical analysis.

\section{Results}

Total polyphenols, flavonoids, condensed tannin contents

The results showed (Figure 1) that S. Officinalis extract

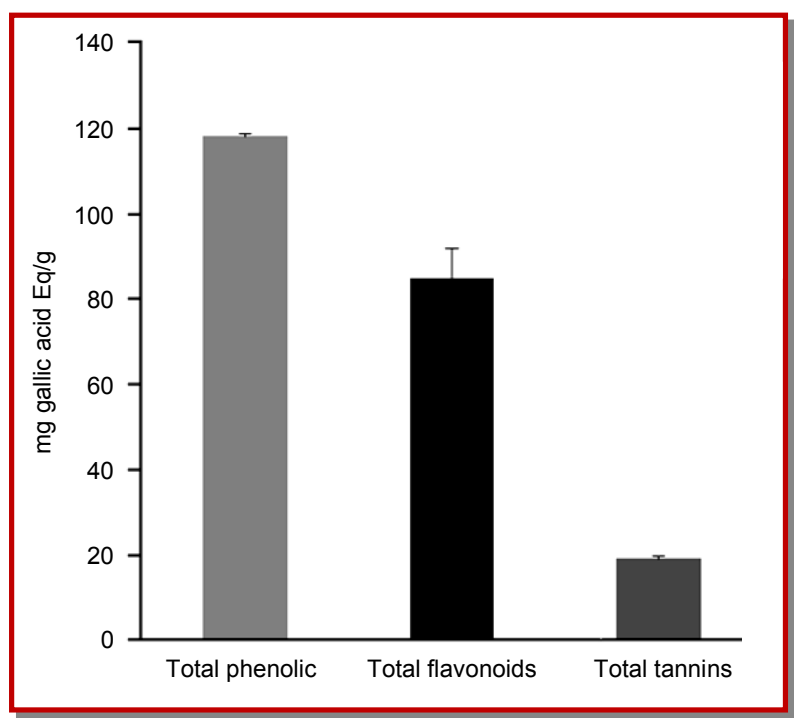

Figure 1: Total phenols, total flavonoids and condensed tannins in S. officinalis methanolic extract. The data represent the mean $\pm \mathrm{SD}$ demonstrated the highest total phenol content with more than $118.2 \pm 0.7 \mathrm{mg}$ gallic acid $\mathrm{Eq} / \mathrm{g}$ dry matter, the flavonoid concentration $(84.7 \pm 7.0 \mathrm{mg}$ gallic acid $\mathrm{Eq} / \mathrm{g}$ dry matter) and the tannins content was estimated at $19.1 \pm 0.7 \mathrm{mg}$ catechin $\mathrm{Eq} / \mathrm{g}$ dry matter.

\section{DPPH Free radical scavenging activity}

The effects of methanolic extract of $S$. officinalis in the $\mathrm{DPPH}$, iron (II) chelating activity and $\beta$-carotene/ linoleic acid bleaching assay are shown in Figure 2, which was comparable to that of the standard antioxidant butylated hydroxytoluene, quercetin, vitamin $\mathrm{C}$ and $\mathrm{E}$. As the better anti-oxidant activity was reflected by the lower $\mathrm{IC}_{50}$ values, the results showed that methanolic extract exhibited the highest anti-oxidant activity. The lowest $\mathrm{IC}_{50}$ was obtained with reducing power assay: $\mathrm{IC}_{50}$ values of $0.334 \pm 0.007 \mathrm{mg} / \mathrm{mL}$, followed by $\beta$-carotene/linoleic acid bleaching assay
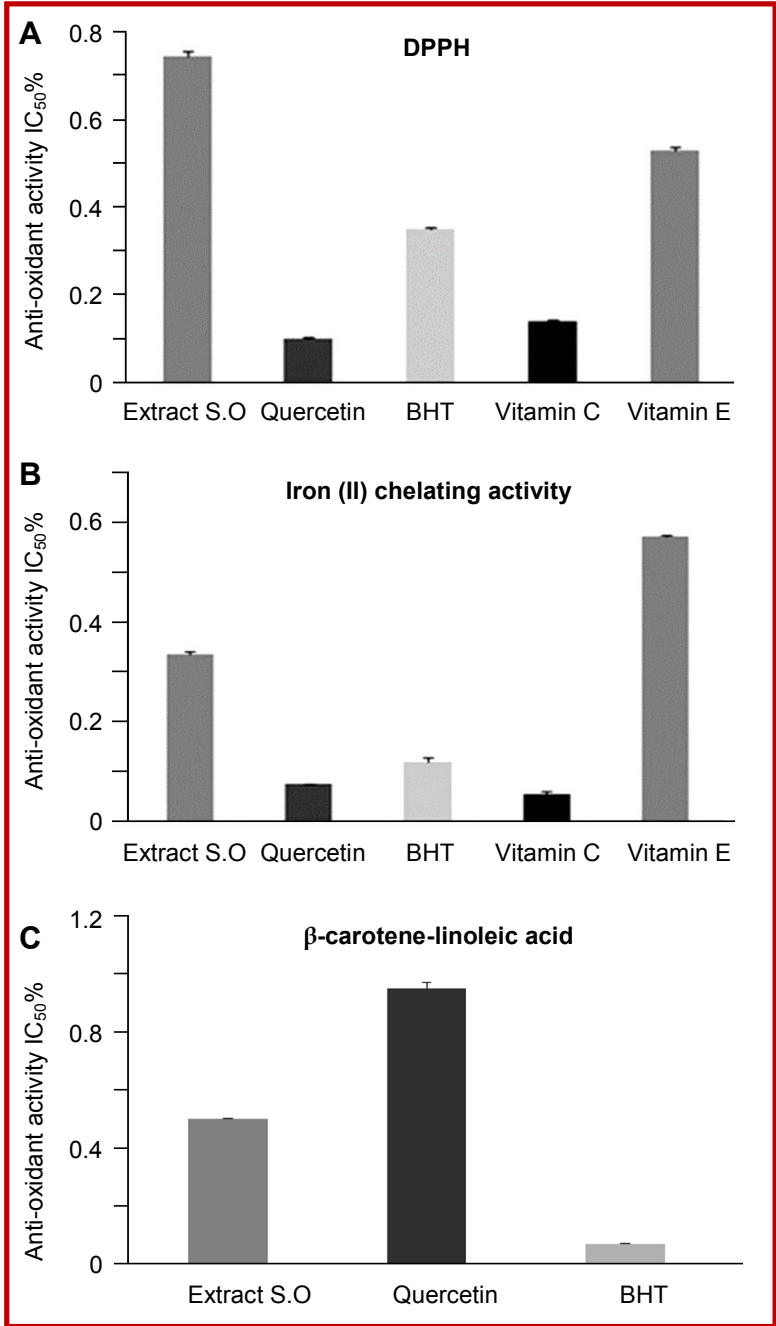

Figure 2: Anti-oxidant activity of $S$. officinalis extract by DPPH (A), Iron (II) chelating activity (B) and $\beta$-carotene/ Linoleic Acid Bleaching assay (C). Each value represents a mean \pm SD $(n=3)$ 


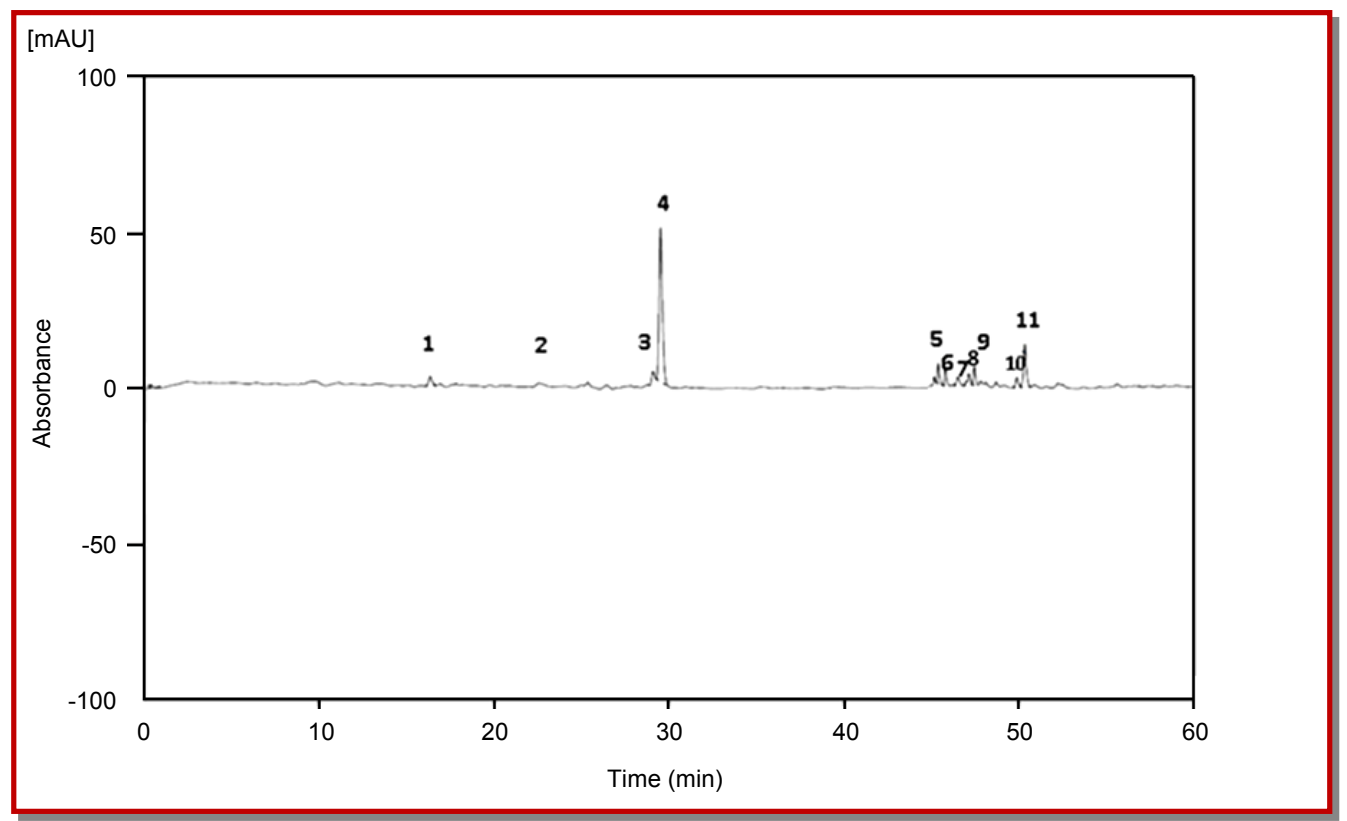

Figure 3. HPLC chromatogram of at 280 overlaid. Peaks: 1, caffeic acid; 2,p-coumaric acid; 3, Rutin; 4, rosmarinic acid; 5,Quercetin; 6, luteolin; 7,apigenin; 8, carnosol; 9, carnosic acid; 10, 11, not identified

$\mathrm{IC}_{50}$ values $0.5 \pm 0.002 \mathrm{mg} / \mathrm{mL}$ and then $\mathrm{DPPH}$ free radical scavenging test system $\left(\mathrm{IC}_{50}=0.741 \pm 0.011 \mu \mathrm{g} /\right.$ $\mathrm{mL})$.

\section{HPLC analysis of S. Officinalis extract}

According to the HPLC data shown in Figure 3, the extract of S. officinalis contained flavonoids and phenolic acid derivatives in different proportions. Eleven phenolic compounds were identified. Among the compounds, rosmarinic and caffeic acid were the most abundant.

\section{Acute toxicity}

The oral administration of S. officinalis extract at doses up to $5 \mathrm{~g} / \mathrm{kg}$ did not produce any mortality symptoms of toxicity in mice during the study period of 14 days.

\section{Lesion site verification}

The histological analysis by Nissl staining technique done on rat brains sections from the lesioned animals revealed the lesions affected the dorsal hippocampus unilateral damage of dorsal hippocampus. Picture of

\section{Table I}

\section{Effects of S. officinalis extract in the presence or absence of hippocampus lesion}

\begin{tabular}{|c|c|c|c|c|c|c|c|c|c|c|}
\hline & \multicolumn{10}{|c|}{ Sequences } \\
\hline & 1 & 2 & 3 & 4 & 5 & 6 & 7 & 8 & 9 & 10 \\
\hline Control & $0.3 \pm 0.2$ & $1.5 \pm 0.3$ & $3.8 \pm 0.3$ & $4.8 \pm 0.2$ & $5.2 \pm 0.2$ & $5.8 \pm 0.3$ & $6.8 \pm 0.3$ & $7.0 \pm 0.0$ & $7.3 \pm 0.3$ & $8.3 \pm 0.3$ \\
\hline Sham & $0.2 \pm 0.2$ & $1.2 \pm 0.5$ & $4.0 \pm 0.4$ & $5.2 \pm 0.2$ & $8.2 \pm 0.5$ & $10.0 \pm 0.0$ & $9.8 \pm 0.2$ & $8.0 \pm 0.0$ & $7.0 \pm 0.0$ & $8.3 \pm 0.3$ \\
\hline Sage $(50 \mathrm{mg} / \mathrm{kg})$ & $2.3 \pm 0.4$ & $2.8 \pm 0.5$ & $3.8 \pm 0.3$ & $5.2 \pm 0.2$ & $6.2 \pm 0.2$ & $6.7 \pm 0.3$ & $6.8 \pm 0.3$ & $7.5 \pm 0.3$ & $8.2 \pm 0.3$ & $8.7 \pm 0.3$ \\
\hline Sage $(100 \mathrm{mg} / \mathrm{kg})$ & $3.0 \pm 0.4$ & $3.3 \pm 0.3$ & $4.3 \pm 0.3$ & $5.3 \pm 0.2$ & $6.8 \pm 0.2^{a}$ & $6.8 \pm 0.3$ & $7.0 \pm 0.0^{\mathrm{a}}$ & $7.7 \pm 0.3$ & $8.7 \pm 0.3$ & $8.9 \pm 0.3$ \\
\hline Sage $(200 \mathrm{mg} / \mathrm{kg})$ & $2.7 \pm 0.5$ & $4.7 \pm 0.2$ & $4.2 \pm 0.3$ & $5.7 \pm 0.2$ & $7.0 \pm 0.3$ & $6.7 \pm 0.3^{a}$ & $7.2 \pm 0.3$ & $7.8 \pm 0.3$ & $8.5 \pm 0.3$ & $9.2 \pm 0.3$ \\
\hline Lesioned & $0.2 \pm 0.2^{a}$ & $0.3 \pm 0.2$ & $1.7 \pm 0.2$ & $3.0 \pm 0.3 b$ & $3.5 \pm 0.2^{b}$ & $4.7 \pm 0.3$ & $4.5 \pm 0.3$ & $4.3 \pm 0.4^{\mathrm{a}}$ & $4.0 \pm 0.3$ & $4.5 \pm 0.3$ \\
\hline $\begin{array}{l}\text { Sage }(50 \mathrm{mg} / \mathrm{kg}) \\
\text { + Lesioned }\end{array}$ & $5.7 \pm 0.4 \mathrm{~b}, \mathrm{~d}$ & $5.7 \pm 0.4^{\mathrm{b}, \mathrm{d}}$ & $6.0 \pm 0.4^{\mathrm{b}, \mathrm{d}}$ & $6.3 \pm 0.2^{b, d}$ & $6.5 \pm 0.2^{b, d}$ & $6.5 \pm 0.3$ & $6.7 \pm 0.3+$ & $6.8 \pm 0.3$ & $7.2 \pm 0.3$ & $7.3 \pm 0.3$ \\
\hline $\begin{array}{l}\text { Sage }(100 \mathrm{mg} / \mathrm{kg}) \\
\text { + Lesioned }\end{array}$ & $6.2 \pm 0.3 \mathrm{~b}, \mathrm{~d}$ & $5.8 \pm 0.3^{b, d}$ & $6.5 \pm 0.2^{\mathrm{b}, \mathrm{d}}$ & $6.7 \pm 0.2^{\mathrm{bd}}$ & $6.7 \pm 0.2^{\mathrm{bd}}$ & $6.7 \pm 0.3 c$ & $6.8 \pm 0.3^{c}$ & $7.3 \pm 0.3+$ & $7.2 \pm 0.3 c$ & $7.7 \pm 0.3 c$ \\
\hline $\begin{array}{l}\text { Sage }(200 \mathrm{mg} / \mathrm{kg}) \\
\text { + Lesioned }\end{array}$ & $6.2 \pm 0.3^{\mathrm{b}, \mathrm{d}}$ & $6.0 \pm 0.3^{b, d}$ & $6.5 \pm 0.2^{b, d}$ & $6.8 \pm 0.2$ & $6.8 \pm 0.2^{c}$ & $6.8 \pm 0.3^{c}$ & $7.0 \pm 0.0^{c}$ & $7.5 \pm 0.3+$ & $8.2 \pm 0.4+$ & $7.7 \pm 0.3 c$ \\
\hline
\end{tabular}




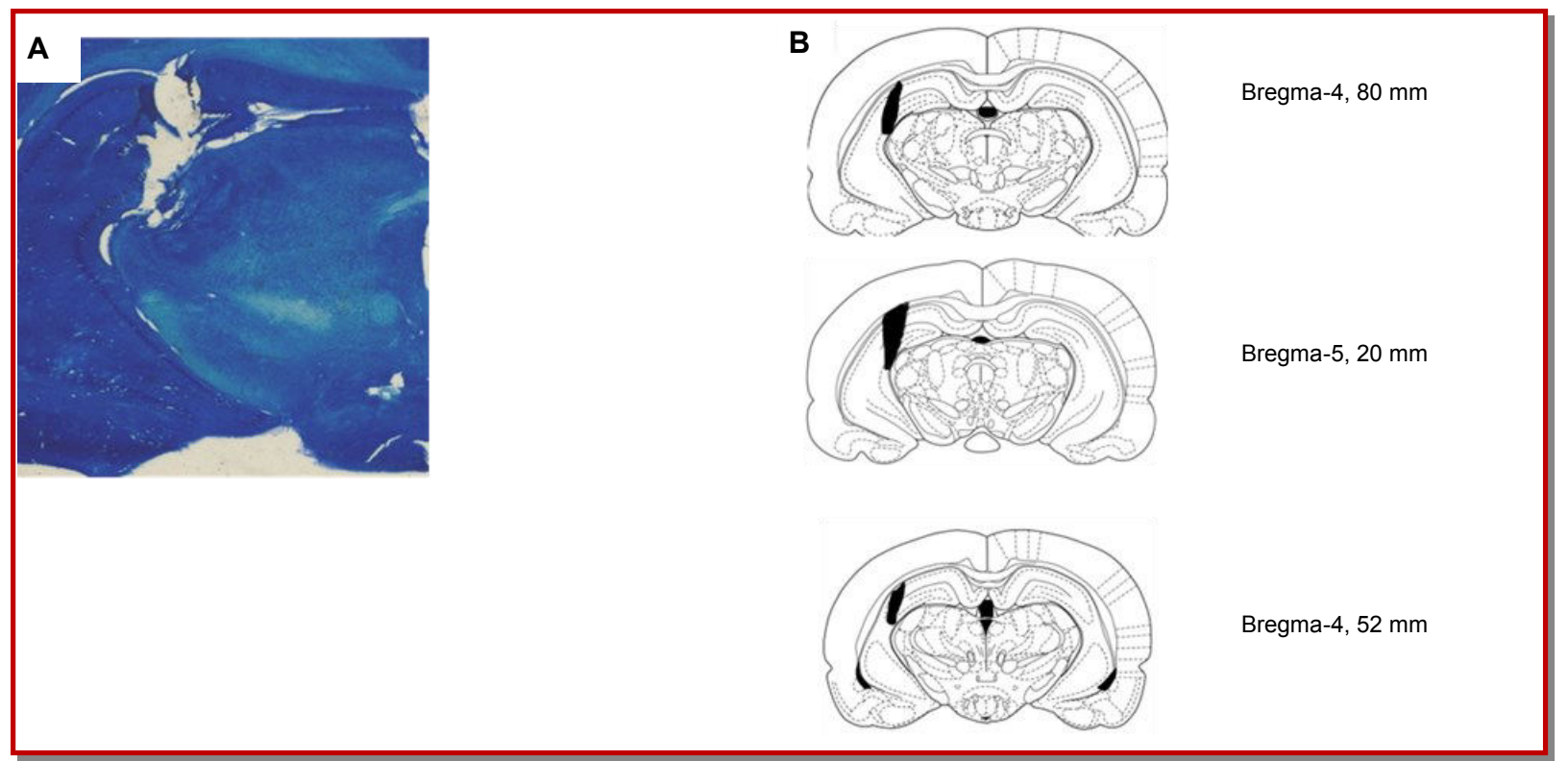

Figure 4: (A) Photomicrographs of coronal Nissl-stained sections from a representative hippocampus lesioned rat. (B). Serial histological reconstructions of representative extent (Black) of electrolytic lesions in hippocampus in the rat according to Paxinos and Watson, 1998. Numbers indicate distance posterior from bregma according to Paxinos and Watson, 1998.
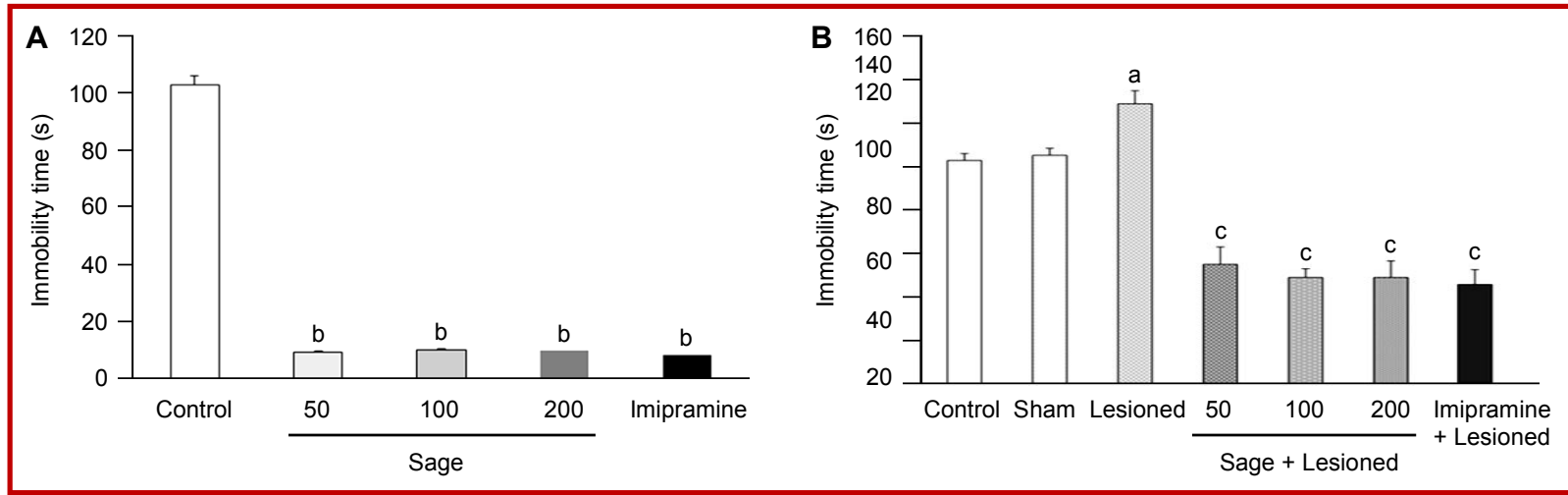

Figure.5. Effect of S. officinalis methanolic extract (50,100 and $200 \mathrm{mg} / \mathrm{kg}$ i.p.) or imipramine (30 mg/ $\mathrm{kg}$ i.p.) on forced swim test immobility time in intact and hippocampal-lesioned rats.

Sage methanolic extract or imipramine was injected $30 \mathrm{~min}$ before the test. Control group received saline 30 min before the test. Graph A and B shows the duration of immobility in the different tested groups, after treatment with Sage extract or imipramine. Data represent means \pm S.E.M, of immobility during the 6 -min test session $(\mathrm{n}=6$ rats per group). Comparisons were made by using a one-way ANOVA followed by post hoc Tukey test: ap $<0.05$, bp $<0.001$ compared with control group, $\mathrm{c} p<0.001$ compared with lesioned group.

the representative lesions are presented in Figure 4A and representative schematic drawings of the brains of the animals with lesions are shown in Figure 4B.

Four rats from lesioned and sage plus lesioned group were excluded from statistical analysis for the forced swimming test, whereas two rats from each group. The lesioned group and sage plus lesioned group were excluded from statistical analysis for the conditioned learning.

\section{Antidepressant-like activity of S. officinalis extract}

In the forced swim test, we investigated the anti- depressant like effect of sage extract in both intact and hippocampal-lesioned animals.

The results presented in Figure 5 (A) show that the immobility duration of treated groups with sage at different doses $(50,100$ and $200 \mathrm{mg} / \mathrm{kg}$ ) or imipramine (30 $\mathrm{mg} / \mathrm{Kg}$, intraperitoneally), was shorter than the control group, $[\mathrm{H}(10.6)=29.7 ; \mathrm{p}=<0.001]$, and the treatment with sage extract reached roughly the same result observed in positive control treated with imipramine (30 mg/kg, intraperitoneally).

Post hoc comparisons revealed a significant higher total time of immobility in lesioned group as compared with 

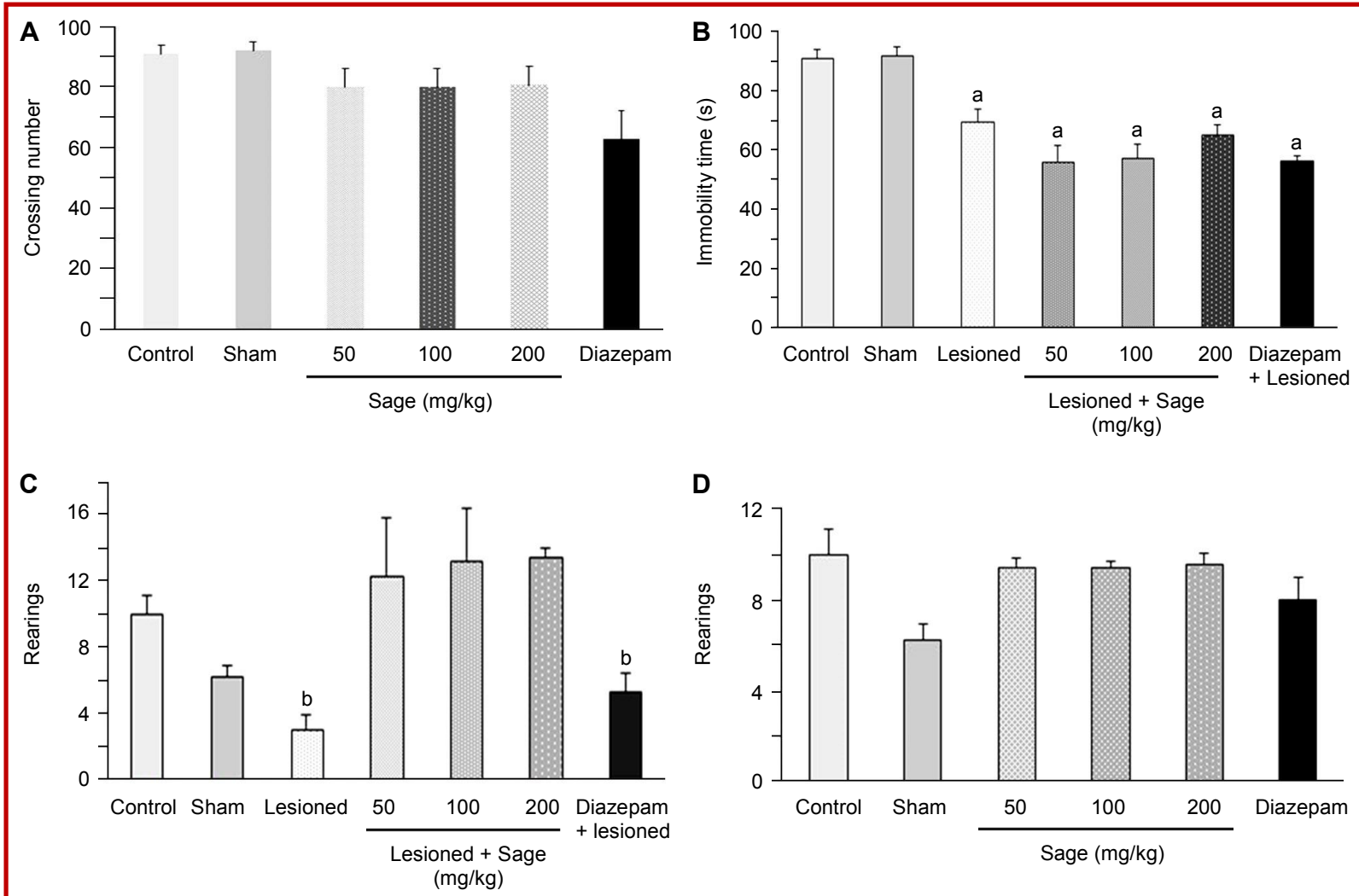

Figure 6: Open-field activity of rats. Intact and hippocampal-lesioned were treated with S. officinalis (50, $100 \mathrm{and} 200 \mathrm{mg} / \mathrm{kg}$ i.p) or diazepam (1 mg/kg i.p) (A, B); Number of crossings during the 5 min session. (C,D) Number of rearings during the 5 min session. Values are the means \pm S.E.M. $(n=6)$. a $p<0.001,{ }^{b} p<0.05$ as compared to the normal control group

normal control $(\mathrm{p}<0.05)$ while in the lesioned animals and treated with sage extract $(50,100$ and $200 \mathrm{mg} / \mathrm{kg})$ or imipramine (30 mg/kg, intraperitoneally) a reduction of the same parameter was observed as compared to lesioned group $(\mathrm{p}<0.001)$ (Figure 5B).

\section{Effects on the number of crossing and rearing in the open-field test}

The locomotor activity of extract is evaluated by its effect on open field test. In this test, our results show that treatment with sage or diazepam had no effect on the locomotor activity in open-field test compared to the lesioned animals. Post hoc analysis indicted a significant reduction in the locomotor activity in both lesioned and lesioned treated with sage or diazepam, as compared to the normal control group F (10.55)=12.20; $\mathrm{p}<0.001$ (Figure 6A,B). In the vertical activity (number of rearings), the lesioned and lesioned rat treated with diazepam ( $1 \mathrm{mg} / \mathrm{kg}$, intraperitoneally) showed a significant decrease in the number of rearing as compared to the normal control group, $\mathrm{H}(10.55)=29.04 ; \mathrm{p}<0.05$. The sage treatment did not show any significant effect on these behavioral measurements (Figure 6C,D).

\section{Anxiolytic activity of S. officinalis extract}

The treatment of normal rats with sage extract $(50,100$ and $200 \mathrm{mg} / \mathrm{kg}$ ) or diazepam $(1 \mathrm{mg} / \mathrm{kg})$ reduced significantly the marble-burying behavior compared with the control group $\mathrm{F}(10.55)=78.06, \mathrm{p}<0.001$ (Figure 7A). One the other hand, comparisons using the Tukey's test revealed that lesioned rats buried a significant higher number of marbles as compared to the normal control group, $\mathrm{p}<0.001$. However, when the lesioned animals are treated with diazepam or sage extract a dose-dependent decrease in marble burying behavior was observed ( $\mathrm{p}<0.001$ ) (Figure 7B).

\section{Effect of S. officinalis extract on learning}

In this experiment, the animals were tested using 10 sequences of classic conditioning.

Results of conditioned learning performance represented in Table I indicate that the administration of sage extract (50, 100 and $200 \mathrm{mg} / \mathrm{kg}$ ) showed a significant increase in the number of avoidance response as compared to the normal group which indicated that methanolic extract enhanced acquisition of the task since the seven sequences (sequence 7; F (10.55)=30.10; $\mathrm{p}=0.039$ ). Therefore, statistical analysis revealed that the learning performance of lesioned animals is less than the control group (sequence 3; F $(10.55)=32.67 ; \mathrm{p}<0.001$ ) which is reflected by the decrease of conditioned 


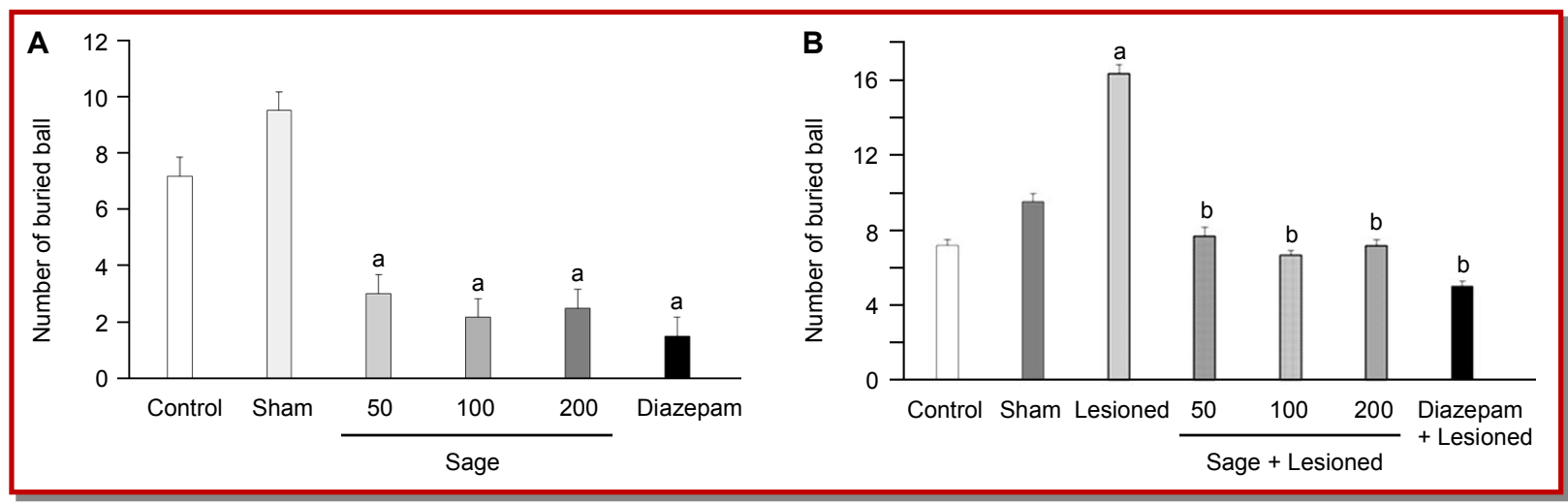

Figure 7: Effects of S. officinalis, methanolic extract (50, 100 and $200 \mathrm{mg} / \mathrm{kg}$ i.p.) or diazepam $(1 \mathrm{mg} / \mathrm{kg}$ i.p.) in the presence or absence of hippocampus lesion on marble-burying behaviour in rats during $30 \mathrm{~min}$. Results are expressed as means \pm S.E.M. (n $=6$ per group)

reactions number during all of the tested sequences. However, the treatment of lesioned animals with three doses 50, 100 and $200 \mathrm{mg} / \mathrm{kg}$ of sage extract a highly significant gradual increase in number of conditioned reactions as compared to the lesioned animals (sequence 4; F $(10.55)=37.27 ; \mathrm{p}<0.001)$. No significant differences between the sham group and the other tested groups $(\mathrm{p}>0.05)$.

\section{Discussion}

Major depression, memory loss and atrophy of the hippocampus are the most deterioration observed in Alzheimer disease (Byers and Yaffe, 2011; Schweitzer et al., 2002), and none of the current treatment can successfully cure (Alzheimer disease) at an early stage. On the other hand, many herbs have pharmacological activities relevant to dementia therapy, like S. officinalis (Howes et al., 2003). It hence the need to evaluate the antidepressant and anxiolytic-like activity of S. officinalis and the effective effect on learning in the presence or absence of hippocampus lesion.

Our present study has shown, for the first time the antidepressant-like effect of methanolic extract from the leaves of S. officinalis in the forced swim test in rats. The i.p. injection of plant extract produced a marked reduction in immobility time. This effect was comparable to the reference antidepressant drug imipramine. These findings proved the antidepressant like effect of this plant at the different tested doses (50,100, $200 \mathrm{mg} /$ $\mathrm{kg}$ ), which could be due to their riches in polyphenolics compounds particularly rosmarinic acid and caffeic acid, confirmed by our HPLC analysis and supported by a previous study (Farhat et al., 2013). On the other hand, further results showed that rosmarinic acid and caffeic acid the major phenol compounds of sage, exerts anti-depressant like effect in an animal model of depression, and reduced the duration of immobility in forced swimming test (Kondo et al., 2015; Takeda et al., 2002). Furthermore, our data showed that methanolic extract possess anti-depressant like effect even in the presence of electrolytic lesion of hippocampus, and could be explained by neuroprotective effect of rosmarinic acid against corticosterone (Sasaki et al., 2013), and in earlier studies rosmarinic acid has antidepressant activity via regulation of $\mathrm{Mkp}-1$, which the expression in hippocampus could be increased by the high glucocorticoid levels in depression (Kim et al., 2005), and modulation of dopamine and corticosterone synthesis (Kondo et al., 2015). On the other hand, the extract had no significant effect on the motor activity as assessed by the open-field test. These data demonstrate that the sage antidepressant-like effect is specific, not due to the psychostimulant effect, which might be considered a false positive result in the forced swimming test (Borsini et al., 1988).

Using the marble burying test, the treatment with sage extract showed anxiolytic effects in hippocampal lesioned and intact rats which was reflected by the reduced number of buried marbles. The defensive burying behaviors in the marble burying test represent an active coping strategy in response to a discrete threat including the predictive validity for anxiety (Gorton et al., 2010), there are some evidence about the possible effects of $S$. officinalis on anxiety. The results of a study on 30 healthy participants showed improvement in mood and reduced anxiety effect following the administration of single doses of $S$. officinalis due to the cholinesterase inhibiting properties of this plant (Kennedy et al., 2006). Some studies about anxiolytic effects of other salvia species showed that S. leriifolia, $S$. reuterana Boiss and $S$. eleganspocess induces anxiolytic effect in rats using EPM model (Herrera-Ruiz et al., 2006; Hosseinzadeh et al., 2008; Mora et al., 2006; Rabbani et al., 2005).

In addition, the present study indicate that methanolic extract of S. officinalis enhance and improve learning of rats and offsetting the negative effect of electrolytic lesion in the hippocampus. These data are in agreement with some other studies reporting that ethanolic extract 
of $S$. officinalis leaves possess a mnemonic effect on adult male rats (Eidi et al., 2006; Tildesley et al., 2005). In our study, these effects were revealed by increase the number of conditioned responses in learning and suggested that $S$. officinalis exhibits central nervous system acetylcholine receptor activity, including nicotinic and muscarinic binding properties (Wake et al., 2000). In addition, several clinical and experimental studies (Eidi et al., 2003; Hasselmo, 2006; Herholz et al., 2005; Muir, 1997; Tang et al., 1997; Winters and Bussey, 2005) have demonstrated the important role of the cholinergic system in learning, memory and attention. The degeneration of the cholinergic system is responsible for reduced acetylcholine esterase and acetylcholine transferase levels and changed distribution of cholinoceptors in brains of patients with Alzheimer disease (Mufson et al., 2008).

Moreover, the bioactive compounds of sage possess anticholinesterase activity (Perry et al., 1996), and the interaction of rosmarinic acid properties like anticholinesterase, neuroprotective, and anti-oxidant which has been confirmed through the DPPH, $\beta$-carotene and the reducing power methods, may all be responsible for the revealed effects of S. Officinalis (Hasanein et al., 2016; Hasanein and Mahtaj, 2015).

These data supply further evidence that the efficacy of S. officinalis extract can be appropriate to the treatment of cognitive disorders (Houghton and Howes, 2005; Sallam et al., 2016) and might potentially provide natural treatment for Alzheimer disease (Akhondzadeh et al., 2003).

\section{Conclusion}

The methanolic extract of S. Officinalis leaves reveal beneficial effects on depression, anxiety and learning of rats in the presence or absence of hippocampus electrolytic lesion.

\section{Ethical Issue}

All experiments were carried out in accordance with the European Community Guidelines (EEC Directive of 24 November 1986; 86/609/EEC). All efforts were made to minimize animal suffering and to reduce the number of animals used.

\section{Conflict of Interest}

No potential conflict of interest was reported by the authors.

\section{Acknowledgement}

The authors are grateful to Mr. A. Regragui for his helpful giving animals and drugs.

\section{References}

Akhondzadeh S, Noroozian M, Mohammadi M, Ohadinia S, Jamshidi AH, Khani M. S. officinalis extract in the treatment of patients with mild to moderate Alzheimer's disease: A double blind, randomized and placebo-controlled trial. J Clin Pharm Ther. 2003; 28: 53-59.

Alarcon-Aguilar FJ, Roman-Ramos R, Flores-Saenz JL, Aguirre -Garcia F. Investigation on the hypoglycaemic effects of extracts of four Mexican medicinal plants in normal and alloxan-diabetic mice. Phyther Res. 2002; 16: 383-86.

Behradmanesh S, Derees F, Rafieian-Kopaei M. Effect of $S$. officinalis on diabetic patients. J Ren Inj Prev. 2013; 2: 51-54.

Borsini F, Lecci A, Mancinelli A, D'Aranno V, Meli A. Stimulation of dopamine D-2 but not D-1 receptors reduces immobility time of rats in the forced swimming test: implication for antidepressant activity. Eur J Pharmacol. 1988; 148: 301-07.

Byers AL, Yaffe K. Depression and risk of developing dementia. Nat Rev Neurol. 2011; 7: 323-31.

Deacon RMJ, Rawlins JNP. Hippocampal lesions, speciestypical behaviours and anxiety in mice. Behav Brain Res. 2005; 156: 241-49.

Dekeyne A. Behavioural models for the characterisation of established and innovative antidepressant agents. Th rapie 2005; 60: 477-84.

Dringenberg HC, Hamze B, Wilson A, Speechley W, Kuo MC. Heterosynaptic facilitation of in vivo thalamocortical longterm potentiation in the adult rat visual cortex by acetylcholine. Cereb Cortex. 2006; 17: 839-48.

Eidi M, Eidi A, Bahar M, Effects of S. officinalis L. (sage) leaves on memory retention and its interaction with the cholinergic system in rats. Nutrition 2006; 22: 321-26.

Eidi M, Zarrindast MR, Eidi A, Oryan S, Parivar K. Effects of histamine and cholinergic systems on memory retention of passive avoidance learning in rats. Eur J Pharmacol. 2003; 465: 91-96.

Farhat M Ben, Landoulsi A, Chaouch-Hamada R, Sotomayor JA, Jordan MJ. Characterization and quantification of phenolic compounds and anti-oxidant properties of Salvia species growing in different habitats. Ind Crops Prod. 2013; 49: 90414.

Gorton LM, Vuckovic MG, Vertelkina N, Petzinger GM, Jakowec MW, Wood RI. Exercise effects on motor and affective behavior and catecholamine neurochemistry in the MPTP-lesioned mouse. Behav Brain Res. 2010; 213: 253-62.

Gyertyán I. Analysis of the marble burying response: Marbles serve to measure digging rather than evoke burying. Behav Pharmacol. 1995; 6: 24-31.

Harasawa T, Ago Y, Itoh S, Baba A, Matsuda T. Role of serotonin type $1 \mathrm{~A}$ receptors in fluvoxamine-induced inhibition of marble-burying behavior in mice. Behav Pharmacol. 2006; $17,637-640$.

Hasanein P, Felehgari Z, Emamjomeh A. Preventive effects of S. officinalis L. against learning and memory deficit induced by diabetes in rats: Possible hypoglycaemic and anti-oxidant 
mechanisms. Neurosci Lett. 2016; 622: 72-77.

Hasanein P, Mahtaj AK. Ameliorative effect of rosmarinic acid on scopolamine-induced memory impairment in rats. Neurosci Lett. 2015; 585: 23-27.

Hasselmo ME. The role of acetylcholine in learning and memory. Curr Opin Neurobiol. 2006; 16: 710-15.

Hedlund PB, Sutcliffe JG. The 5-HT7 receptor influences stereotypic behavior in a model of obsessive-compulsive disorder. Neurosci Lett. 2007; 414: 247-51.

Herholz K, Weisenbach S, Kalbe E, Diederich NJ, Heiss WD. Cerebral acetylcholine esterase activity in mild cognitive impairment. Neuroreport 2005; 16: 1431-34.

Herrera-Ruiz M, García-Beltrán Y, Mora S, Díaz-Véliz G, Viana GSB, Tortoriello J, Ramírez G. Antidepressant and anxiolytic effects of hydroalcoholic extract from Salvia elegans. J Ethnopharmacol. 2006; 107: 53-58.

Ho YJ, Eichendorff J, Schwarting RKW. Individual response profiles of male Wistar rats in animal models for anxiety and depression. Behav Brain Res. 2002; 136: 1-12.

Hosseinzadeh H, Danaee A, Ziaee T. Anti-anxiety effect of aqueous and ethanolic extracts of Salvia leriifolia benth. leaves in mice using elevated plus maze. J Med Plants. 2008; 3: $25-36$.

Houghton PJ, Howes MJ. Natural products and derivatives affecting neurotransmission relevant to Alzheimer's and Parkinson's disease. Neurosignals 2005; 14: 6-22.

Howes MJR, Perry NSL, Houghton PJ. Plants with traditional uses and activities, relevant to the management of Alzheimer's disease and other cognitive disorders. Phyther Res. 2003; 17: 1-18.

Katz RJ, Roth KA, Carroll BJ. Acute and chronic stress effects on open field activity in the rat: Implications for a model of depression. Neurosci Biobehav Rev. 1981; 5: 247-51.

Kennedy DO, Pace S, Haskell C, Okello EJ, Milne A, Scholey $\mathrm{AB}$. Effects of cholinesterase inhibiting sage (S. officinalis) on mood, anxiety and performance on a psychological stressor battery. Neuropsychopharmacology 2006; 31: 845-52.

Kennedy DO, Scholey AB, The psychopharmacology of European herbs with cognition-enhancing properties. Curr Pharm Des. 2006; 12: 4613-23.

Kim GS, Choi YK, Song SS, Kim WK, Han BH. MKP-1 contributes to oxidative stress-induced apoptosis via inactivation of ERK1/2 in SH-SY5Y cells. Biochem Biophys Res Commun. 2005; 338: 1732-38.

Kim HG, Oh MS. Herbal medicines for the prevention and treatment of Alzheimer's disease. Curr Pharm Des. 2012; 18: $57-75$.

Kondo S, El Omri A, Han J, Isoda H. Antidepressant-like effects of rosmarinic acid through mitogen-activated protein kinase phosphatase-1 and brain-derived neurotrophic factor modulation. J Funct Foods. 2015; 14: 758-66.

Lu Y, Yeap Foo L. Anti-oxidant activities of polyphenols from sage (S. officinalis). Food Chem. 2001; 75: 197-202.

Mayer B, Baggio CH, Freitas CS, dos Santos AC, Twardowschy A, Horst H, Pizzolatti MG, Micke GA, Heller M, dos Santos
EP, Otuki MF, Marques MCA. Gastroprotective constituents of S. officinalis L. Fitoterapia 2009; 80: 421-26.

Miraliakbari H, Shahidi F. Anti-oxidant activity of minor components of tree nut oils. Food Chem. 2008; 111: 421-27.

Mora S, Millán R, Lungenstrass H, Díaz-Véliz G, Morán JA, Herrera-Ruiz M, Tortoriello J. The hydroalcoholic extract of Salvia elegans induces anxiolytic- and antidepressant-like effects in rats. J Ethnopharmacol. 2006; 106: 76-81.

Mufson EJ, Counts SE, Perez SE, Ginsberg SD. Cholinergic system during the progression of Alzheimer's disease: therapeutic implications. Expert Rev Neurother. 2008; 8: 1703 -18 .

Muir JL. Acetylcholine, aging, and Alzheimer's disease. Pharmacol Biochem Behav. 1997; 56: 687-96.

Nicolas LB, Kolb Y, Prinssen EPM. A combined marble burying-locomotor activity test in mice: A practical screening test with sensitivity to different classes of anxiolytics and antidepressants. Eur J Pharmacol. 2006; 547: 106-15.

Oyaizu M. Studies on products of browning reaction: Antioxidative activities of products of browning reaction prepared from glucosamine. Japanese J Nutr Diet. 1986; 44: 307-15.

Palucha A, Pilc A. Metabotropic glutamate receptor ligands as possible anxiolytic and antidepressant drugs. Pharmacol Ther. 2007; 115: 116-47.

Paxinos G, Watson C. The rat brain in stereotaxic coordinates. Academic Press, San Diego, 1998.

Penso G. Index plantarum medicinalium totius mundi eorumque synonymorum: INPLAMED. O.E.M.F. 1983.

Perry EK, Pickering AT, Wang WW, Houghton PJ, Perry NS. Medicinal plants and Alzheimer's disease: From ethnobotany to phytotherapy. J Pharm Pharmacol. 1999; 51: 52734 .

Perry N, Court G, Bidet N, Court J, Perry E. European herbs with cholinergic activities: Potential in dementia therapy. Int J Geriatr Psychiatry. 1996; 11: 1063-69.

Perry NSL, Houghton PJ, Jenner P, Keith A, Perry EK. Salvia lavandulaefolia essential oil inhibits cholinesterase in vivo. Phytomedicine 2002; 9: 48-51.

Porsolt RD, Le Pichon M, Jalfre M. Depression: A new animal model sensitive to antidepressant treatments. Nature 1977; 266: 730-32.

Rabbani M, Sajjadi SE, Jafarian A, Vaseghi G. Anxiolytic effects of Salvia reuterana Boiss. on the elevated plus-maze model of anxiety in mice. J Ethnopharmacol. 2005; 101: 100-03.

Ramos JMJ. Hippocampal damage impairs long-term spatial memory in rats: Comparison between electrolytic and neurotoxic lesions. Physiol Behav. 2008; 93: 1078-85.

Rodrigues MRA, Kanazawa LKS, das Neves TLM, da Silva CF, Horst H, Pizzolatti MG, Santos ARS, Baggio $\mathrm{CH}$, de Paula Werner MF. Antinociceptive and anti-inflammatory potential of extract and isolated compounds from the leaves of $S$. officinalis in mice. J Ethnopharmacol. 2012; 139: 519-26.

Sallam A, Mira A, Ashour A, Shimizu K. Acetylcholine 
esterase inhibitors and melanin synthesis inhibitors from $S$. officinalis. Phytomedicine 2016; 23: 1005-11.

Sasaki K, Han J, Shimozono H, Villareal MO, Isoda $\mathrm{H}$. Caffeoylquinic acid-rich purple sweet potato extract, with or without anthocyanin, imparts neuroprotection and contributes to the improvement of spatial learning and memory of SAMP8 Mouse. J Agric Food Chem. 2013; 61: 5037-45.

Savelev SU, Okello EJ, Perry EK. Butyryl- and acetylcholinesterase inhibitory activities in essential oils of Salvia species and their constituents. Phyther Res. 2004; 18: 315-24.

Schweitzer I, Tuckwell V, O'Brien J, Ames D. Is late onset depression a prodrome to dementia? Int J Geriatr Psychiatry. 2002; 17: 997-1005.

Shimazaki T, Iijima M, Chaki S. Anxiolytic-like activity of MGS0039, a potent group II metabotropic glutamate receptor antagonist, in a marble-burying behavior test. Eur J Pharmacol. 2004; 501: 121-25.

Singleton VL, Rossi JA. Colorimetry of total phenolics with phosphomolybdic-phosphotungstic acid reagents. Am J Enol Vitic. 1965; 16.

Takeda $H$, Tsuji $M$, Inazu M, Egashira $T$, Matsumiya $T$. Rosmarinic acid and caffeic acid produce antidepressive-like effect in the forced swimming test in mice. Eur J Pharmacol.
2002; 449: 261-67.

Tang Y, Mishkin M, Aigner TG. Effects of muscarinic blockade in perirhinal cortex during visual recognition. Proc Natl Acad Sci USA. 1997; 94: 12667-69.

Tildesley N, Kennedy D, Perry E, Ballard C, Wesnes K, Scholey A. Positive modulation of mood and cognitive performance following administration of acute doses of Salvia lavandulaefolia essential oil to healthy young volunteers. Physiol Behav. 2005; 83: 699-709.

Wake G, Court J, Pickering A, Lewis R, Wilkins R, Perry E. CNS acetylcholine receptor activity in European medicinal plants traditionally used to improve failing memory. J Ethnopharmacol. 2000; 69: 105-14.

Winters BD, Bussey TJ. Removal of cholinergic input to perirhinal cortex disrupts object recognition but not spatial working memory in the rat. Eur J Neurosci. 2005; 21: 2263-70.

$\mathrm{Xu}$ BJ, Chang SKC. A comparative study on phenolic profiles and anti-oxidant activities of legumes as affected by extraction solvents. J Food Sci. 2007; 72: S159-66.

Zhishen J, Mengcheng T, Jianming W. The determination of flavonoid contents in mulberry and their scavenging effects on superoxide radicals. Food Chem. 1999; 64: 555-59. 